\title{
REPRESENTAÇÕES SOCIAIS DO IDOSO \\ QUE PARTICIPA DE GRUPOS PARA TERCEIRA IDADE NO MUNICÍPIO DE SANTA CRUZ DO SUL
}

\author{
Silvia Coutinho Areosa ${ }^{1}$ \\ Patricia Bevilacqua ${ }^{2}$ \\ Juliana Werner ${ }^{2}$
}

\section{Resumo}

Esta pesquisa teve como objetivo verificar como o idoso do município de Santa Cruz do Sul/ RS que freqüenta algum grupo de convivência está representando a sua velhice e quais as influências culturais e regionais sofridas por este segmento. Buscou-se através de um questionário misto (com perguntas fechadas e abertas) respondido por $10 \%$ dos idosos que freqüentam grupos de convivência no município, verificar quem são os idosos de Santa Cruz do Sul que participam de grupos, em que condições eles vivem e como ocupam o seu tempo livre. Este estudo servirá de base para podermos entender como os fatores sócio-culturais influenciam na construção das representações sociais dos idosos.

Palavras-chave: Representações Sociais. Idosos.

\section{Introdução}

Com o passar da idade, a pessoa afirma sua capacidade de crítica, aperfeiçoa seus conhecimentos não só pelo acúmulo da experiência com o trabalho mas também com os contatos humanos.

${ }^{1}$ Mestre em Psicologia Social e da Personalidade pela Pontifícia Universidade Católica (PUC/RS), docente do departamento de Psicologia da Universidade de Santa Cruz do Sul (UNISC), coordenadora da pesquisa. E-mail: sareosa@unisc.br

2 Acadêmicas de Psicologia da UNISC; bolsistas PUIC/UNISC. 
Dentro do processo de envelhecimento as limitações corporais e a consciência da temporalidade são problemáticas fundamentais. Estas aparecem, seguidamente, no discurso dos idosos, variando conforme a sua situação social e estrutura psíquica. Corpo e tempo se entrecruzam produzindo múltiplas velhices influenciadas pelos contextos sociais e políticos (GOLDFARB, 1998).

Para Beauvoir (1990), a noção de projeto de vida é fundamental para pensar a questão da subjetividade e do tempo. A autora diz que os velhos continuam a se identificar com a imagem do que foram em sua juventude. Mesmo dizendo-se agora aposentados, continuam evocando lembranças de seu trabalho, o que lhes garante a convicção de permanecerem imutáveis ao tempo, sinônimo de segurança e afirmação pessoal.

Goldfarb (1998) refere que nas sociedades tradicionais, a figura do velho representava a sabedoria, a paciência; era ele quem detinha a memória coletiva, e que, através da transmissão oral (fala), construía uma narrativa com a qual se incorporava cada indivíduo na história do grupo.

Sabe-se que envelhecer difere de uma pessoa para outra. Existem vários fatores que influenciam o envelhecimento com o passar dos anos, tais como tempo, hereditariedade e meio ambiente.

Conforme dados da Organização das Nações Unidas (ONU), citados por Rajczuk e Castro (1999), nos países desenvolvidos, estima-se um aumento na taxa de crescimento de indivíduos com mais de 65 anos, de 10,5\% para $18,1 \%$, entre 1975 e 2075, enquanto que, nos países subdesenvolvidos, esse crescimento deverá ser de $3,8 \%$ para $17 \%$, sendo a faixa etária que cresce mais rapidamente.

De acordo com os dados do relatório de pesquisa Os Idosos do Rio Grande do Sul (RIO GRANDE DO SUL, 1997), a partir da década de 60, observa-se um envelhecimento da população brasileira. Esse processo devese a vários fatores, mas principalmente ao declínio da fecundidade e da mortalidade nas faixas etárias mais elevadas. Estes dois fatores, associados à melhoria das condições de saneamento básico e dos avanços técnico-científicos na área da saúde, faz com que a esperança de vida da população aumente, assim como a proporção de idosos. Os censos demográficos do Instituto Brasileiro de Geografia e Estatística (2002) têm demonstrado o aumento da população idosa $(9,1 \%$ no Rio Grande do Sul). Há, portanto, a 
necessidade de que mudemos a idéia de que somos um país e um estado somente de jovens.

Torna-se importante a produção social de mecanismos facilitadores no encaminhamento e destino de um fato social como este da velhice, bem como o incremento, a nível de pesquisas nesta área. Surge também a necessidade de tratar as questões de gênero na velhice. Até agora, o idoso era considerado como uma categoria única e, portanto, independente do sexo ou do contexto social, econômico e cultural (SANTOS; BELO, 2000).

A representação social da pessoa envelhecida passou por uma série de modificações ao longo do tempo, uma vez que as mudanças sociais reclamavam políticas sociais para a velhice, políticas essas que pressionavam pela criação de categorias classificatórias adaptadas à nova condição moral, assim como a construção ética do objeto velho.

\section{Representações Sociais e Velhice}

Neste estudo utiliza-se a definição das representações sociais como foram descritas por Moscovici (1961), compreendendo um sistema de valores, de noções e de práticas sociais relativas a objetos sociais.

Segundo Guareschi (2000) as representações sociais são saberes práticos e devem ser buscados nas práticas cotidianas dos diversos grupos sociais. Segundo o autor, a relação entre a fala e a ação é fundamental para compreendermos o campo representacional.

Para Teixeira, Schulze e Camargo (2002) as representações sociais são um conjunto de idéias, conceitos que surgem entre os indivíduos para explicar fenômenos que não lhes são familiares.

Ao analisar o conceito de velhice ao longo dos tempos, percebe-se que existem muitas controvérsias. Se considerarmos como um conjunto de ocorrências que representam o declínio global das funções físicas, intelectuais, sociais e emocionais, ela tenderia somente a ocorrer após os 70 anos. O que se constata é que na realidade a pessoa começa a envelhecer sem se dar conta.

Conforme Oliveira, Pasian e Jacquemin (2001) o processo de envelhecimento é historicamente considerado através de duas vertentes: uma que o reconhece como sendo a etapa final da vida, a fase que culmina com a morte; e outra que o entende como a fase da sabedoria, da maturidade e 
serenidade. Os autores relatam que sua pesquisa serve para derrubar o preconceito da velhice como uma fase de desvitalização, bem como a convicção errônea dos idosos como sujeitos carentes, que não possuem elementos para oferecer e que estão somente esperando a morte chegar.

Já com as modificações que ocorreram no âmbito social a partir do séc. XVIII, tendo culminado com a revolução industrial, há uma grande mudança de valores e o indivíduo passa a ter valor quase que exclusivamente por aquilo que produz. Assim, vai surgindo uma sociedade individualista, onde o velho, por não mais produzir a vida e nem riquezas, não vale mais nada, "[ . . . ] o valor social da velhice passa então a ser associado a inutilidade e a decrepitude." (OLIVEIRA; PASIAN; JACQUEMIN, 2001, p. 25)

Para Guimarães (1997), à medida que a pessoa envelhece, ela precisa construir inúmeras versões do seu self para garantir representações multifacetadas de si próprio e um melhor sucesso no curso da vida. $\mathrm{O}$ autor diz que em sua pesquisa lhe chamou atenção o significado que os entrevistados atribuíram ao envelhecimento, como "curso natural de vida" (encontrado em 354 representações sociais sobre o termo envelhecimento).

Estudando as representações sociais, os pesquisadores podem identificar as diferentes visões e interpretações da realidade social que está em constante mudança.

Geralmente considerado um problema para a sociedade, o idoso raramente consegue manter uma solidariedade familiar e social. Com o passar dos anos, o círculo de relações familiares e as amizades tendem a diminuir, seja pela própria dispersão, seja pela proximidade da morte. Dessa forma, muitos acabam se sentindo inúteis, marginalizados da vida comunitária. Ninguém vê o mundo através de seus olhos para poder compreendê-los, para reintegrá-los às relações sociais comunitárias e familiares.

A sociedade rotula a velhice como uma forma de estagnação, ironizando-a em suas atividades amorosas, sexuais, físicas e sociais. Por outro lado, exige atitudes tais como: serenidade, tranqüilidade e passividade, vestuário sóbrio, decência de maneiras e respeito pelas aparências. Neste aspecto, alguns elementos devem ser considerados: na família, o idoso é tratado, em muitos casos, como um mero objeto incômodo e inútil, enfim, como alguém desprezível (merecendo, inclusive, maus-tratos). Quando as atenções se dirigem a ele, são camufladas por uma irônica benevo- 
lência, havendo uma duplicidade na atitude prática do adulto com relação aos velhos. O adulto, diante da moral oficial imposta nestes últimos séculos, vê-se forçado, até certo ponto, a respeitá-los, até porque, muitas vezes, necessita do seu auxílio financeiro. Convém-lhe, entretanto, tratá-los como seres inferiores e convencê-los de sua própria decadência. Empenhar-se-á em fazer o idoso sentir e reconhecer suas deficiências, a fim de que o velho lhe ceda a gestão dos negócios, lhe poupe os conselhos e se conforme com um papel passivo.

A Terceira Idade, conforme Santos e Vaz (1997), é uma fase da vida marcada por vários estereótipos, tais como a passividade, a improdutividade, a assexualidade, a degeneração orgânica e psíquica, além da desvinculação com o futuro, o que leva à alienação. Para eles, à medida que as capacidades orgânicas e psíquicas diminuem, o idoso se retrai para não entrar em conflito com o ambiente e sobretudo consigo mesmo. Assim, voltado apenas para suas necessidades, não interfere no ambiente e, portanto, não sofre exigências do mesmo. Esse afastamento do idoso cumpre um importante papel social, ou seja, de oferecer espaço no mercado de trabalho aos mais jovens.

A velhice humana é um fenômeno social que se alterou substancialmente. Entretanto, é vista como em épocas medievais, onde envelhecer era mesmo exceção. Isto significa que as condutas sociais perniciosas resistem às mudanças. Somente uma interessante e persistente ação pode modificar os vícios sociais e/ou introduzir condutas inovadoras, inclusive em relação ao mercado de trabalho.

Magalhães (1989) observa que diferentes imagens sociais do idoso e do processo de envelhecimento são produzidos em função dos determinantes sociais nos quais os indivíduos estão inseridos. Conforme os fatores envolvidos, os significados e valores associados ao uso de determinado conceito podem variar, modificando, construindo e associando representações.

Debert (1994) relata que a tendência das pesquisas referentes a gênero e envelhecimento é enfatizar os fatores psicológicos na velhice, considerando que a androgenia caracteriza as etapas mais avançadas da vida. $\mathrm{Pa}$ péis sociais, valores e atitudes considerados tipicamente masculinos ou femininos, tenderiam a se misturar na velhice. No entanto, o novo enfoque dado à questão do envelhecimento tende a transformar essa experiência em algo radicalmente diferente para homens e mulheres. A autora ressalta que a dife- 
rença na forma como homens e mulheres representam o que é velhice, percebendo as mudanças ocorridas no processo de envelhecimento nos contextos urbanos brasileiros, são elementos fundamentais para se entender as diferenças de gênero no envelhecer.

\section{Método}

Enfocar uma realidade e analisá-la só é possível através de uma construção histórica e ideológica, segundo critérios descritos por Minayo (1987) para a pesquisa social. A autora afirma que o objeto de pesquisa é necessariamente histórico, válido para determinada realidade, em determinado momento e enquadramento. A escolha do objeto é sempre ideológica, porque a análise e o entendimento dos fatos dependem da visão de mundo do próprio pesquisador ou da linha de pesquisa adotada. Os fenômenos sociais têm diferentes leituras, de acordo com as lentes utilizadas, processo esse denominado interpretação.

Para Spink (1999), o mais importante é a visibilidade dada ao processo de interpretação, que passa a ter o caráter de inacabado, "[ . . . ] reinventando-se a cada nova trama engendrada, redescobrindo-se em formas e conteúdos de possibilidades infinitas." (p. 99).

Este estudo iniciou em março de 2002, quando entrou-se em contato com a Prefeitura Municipal de Santa Cruz do Sul para identificar quais eram os grupos de convivência para Terceira Idade cadastrados. Após a identificação dos grupos, fez-se contato com os coordenadores dos mesmos, a fim de conseguir permissão para ir até um de seus encontros, explicar os objetivos da pesquisa e pedir autorização para que ela fosse realizada durante os encontros.

A amostra foi espontânea, composta por aqueles que quiseram participar da pesquisa, chegando ao percentual desejado que era de $10 \%$ dos integrantes de cada grupo de convivência. O questionário era composto por 20 questões (com perguntas abertas e fechadas) que tentavam averiguar como este idoso vive e quais as principais diferenças por gênero em relação à escolaridade, profissão, busca de informação, ocupação do tempo, aposentadoria e saúde. Foi feito um pré-teste do instrumento em dois grupos (de hipertensos) que não fizeram parte da amostra. 
O instrumento de coleta de dados foi aplicado durante os encontros dos grupos nos meses de junho, julho e agosto de 2002, em 150 idosos de ambos os sexos, com idade acima de 60 anos. Estes eram participantes dos 15 (quinze) grupos de convivência para terceira idade cadastrados junto à Prefeitura Municipal e 2 (dois) grupos (Dançar na Terceira Idade e Hidroginástica para Terceira Idade) que são desenvolvidos pela Universidade de Santa Cruz do Sul (UNISC). Dos questionários aplicados, 147 foram validados e seus dados encontram-se em fase de análise, feita através do programa Statistical Package for Social Sciences (SPSS), onde estão sendo criadas tabelas diferenciadas por sexo, para poder estabelecer correlações entre variáveis e caracterizar quem é o idoso que faz parte desta pesquisa, sendo os resultados parciais apresentados neste artigo.

\section{Resultados Encontrados}

Dentre a amostra que fez parte deste estudo, pode-se observar muitos aspectos de sua vida e seu comportamento, que vêm organizados a seguir em gráficos com a freqüência de respostas.

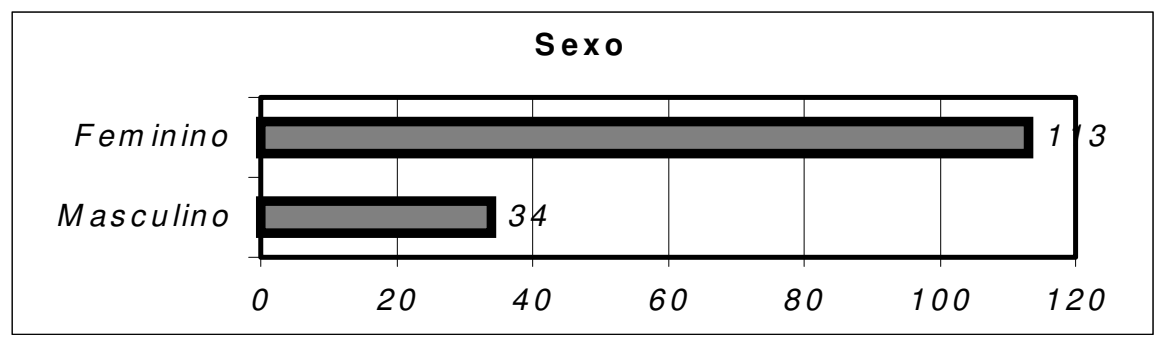

GRÁFICO 1: Identificação por sexo (N=147)

Fonte: Pesquisa de Campo

Percebe-se através do Gráfico 1 que a amostra foi composta por 113 sujeitos do sexo feminino e 34 do sexo masculino, perfazendo um total de 147 pesquisados. Conforme os dados acima, podemos verificar que a maioria $(77 \%)$ dos idosos pesquisados são do sexo feminino, o que é representativo do que ocorre nos grupos de convivência do município, nesta faixa etária, onde 92\% são mulheres (AREOSA; OHLWEILER, 2000).

Quanto à idade, neste estudo, considerou-se como idosos pessoas com mais de 60 anos de idade, conforme a definição da Organização Mun- 
dial da Saúde (OMS) para países em desenvolvimento, embora tenha-se encontrado participantes dos grupos com idade inferior a essa. Esta parece ser uma tendência nos grupos de terceira idade neste município, pois dados semelhantes foram encontrados em uma pesquisa intitulada $O$ Idoso e os Grupos de Convivência no Município de Santa Cruz do Sul, no ano de 1999 (AREOSA; OHLWEILER, 2000).

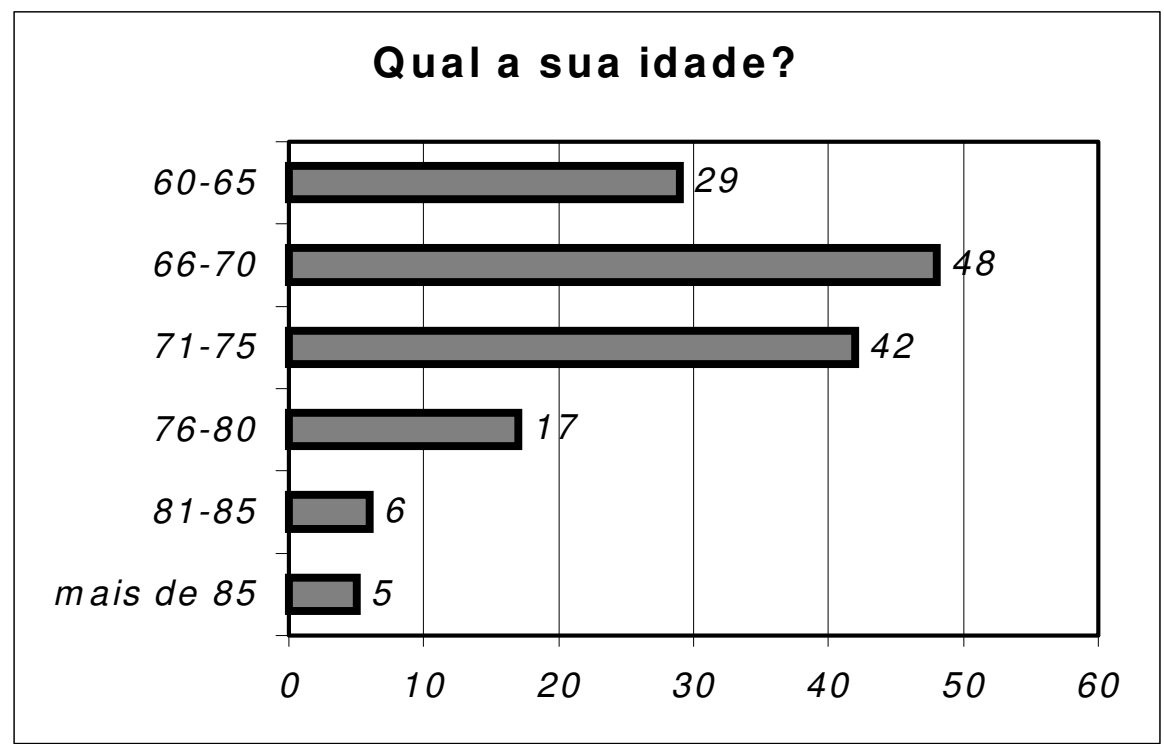

GRÁFICO 2: Idade ( $\mathrm{N}=147)$

Fonte: Pesquisa de Campo

Analisando os dados, encontrou-se $33 \%$ dos idosos na faixa etária entre 66 e 70 anos, $29 \%$ entre 71 e 75 anos; $4 \%$ entre 81 e 85 anos e $3 \%$ com mais de 85 anos, somando, assim, um percentual de $7 \%$ com idade superior a 80 anos (Gráfico 2). Quanto à categorização por idade, novos recortes são propostos por Debert (1999, p. 93): “[ . . . ] jovens idosos (6575 anos); idosos-idosos (acima de 75 anos), como quer Uhlemberg (1987); ou, ainda, idosos mais idosos (com mais de 85 anos), como sugere Johnson (1987), dariam ao envelhecimento recortes diferenciados mais significativos."

Para a autora, na população idosa, é sobretudo o grupo com 85 anos ou mais que terá um crescimento maior nas próximas décadas. As redes de parentesco, pela primeira vez na história, contarão com um número maior de velhos do que de jovens, ao mesmo tempo em que os casados tenderão a ter um número de filhos menor que o número de pais idosos. Debert (1999) 
alerta para o fato de que os idosos muito idosos terão sua velhice marcada pela pauperização, pela passividade e pela dependência. Refere que as formas inovadoras de moradia e de associações são limitadas para esse grupo, e a precariedade das políticas públicas a ele destinadas faz com que o peso de sua situação recaia nos ombros dos filhos e parentes.

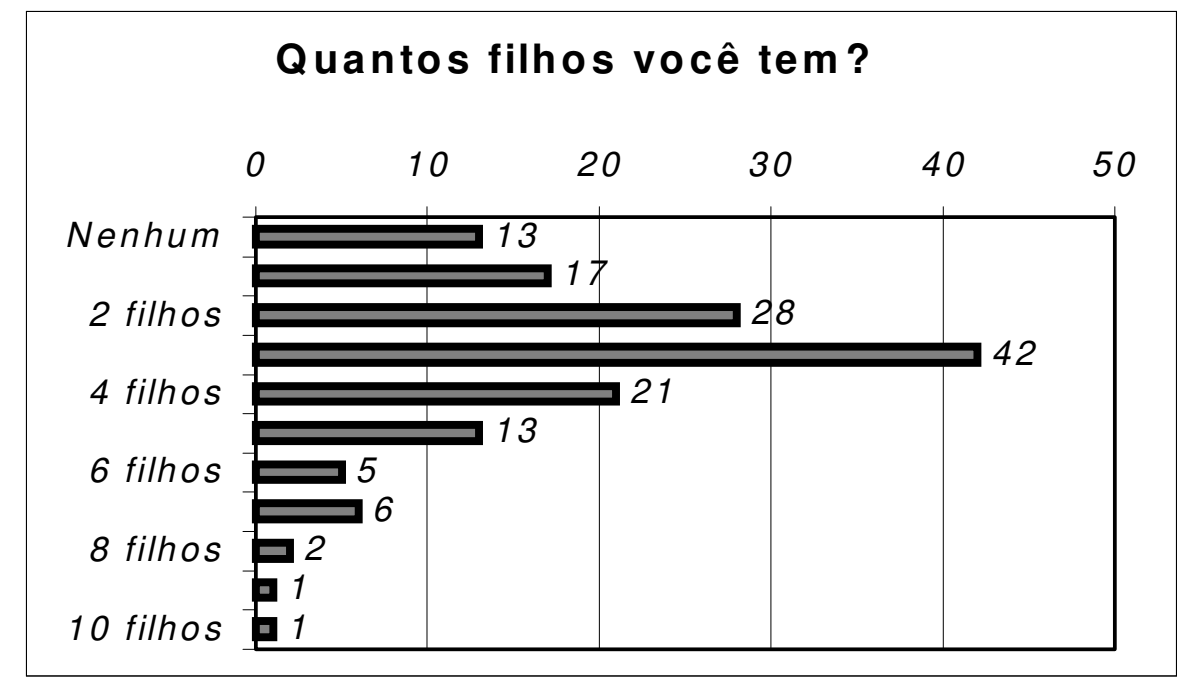

GRÁFICO 3: Número de filhos (N=147)

Fonte: Pesquisa de Campo

Em relação ao número de filhos, $29 \%$ possuem 3 filhos e $19 \%$ possuem 2 filhos, já se constatando uma diminuição na taxa de fecundidade desta população (Gráfico 3). Chaimowicz (1997) refere que em 2020, quando a esperança de vida ao nascer estiver alcançando 75,5 anos, a população será formada por cerca de $23,5 \%$ de jovens e $7,7 \%$ (ou 16,2 milhões) de idosos. Por volta de 2080, a proporção de jovens e idosos deverá se estabilizar e, a partir de então, novos incrementos na proporção de idosos dependerão não mais do declínio da fecundidade, mas da redução da mortalidade após os 64 anos, como já ocorre hoje em países como Suécia, Inglaterra e Estados Unidos. 


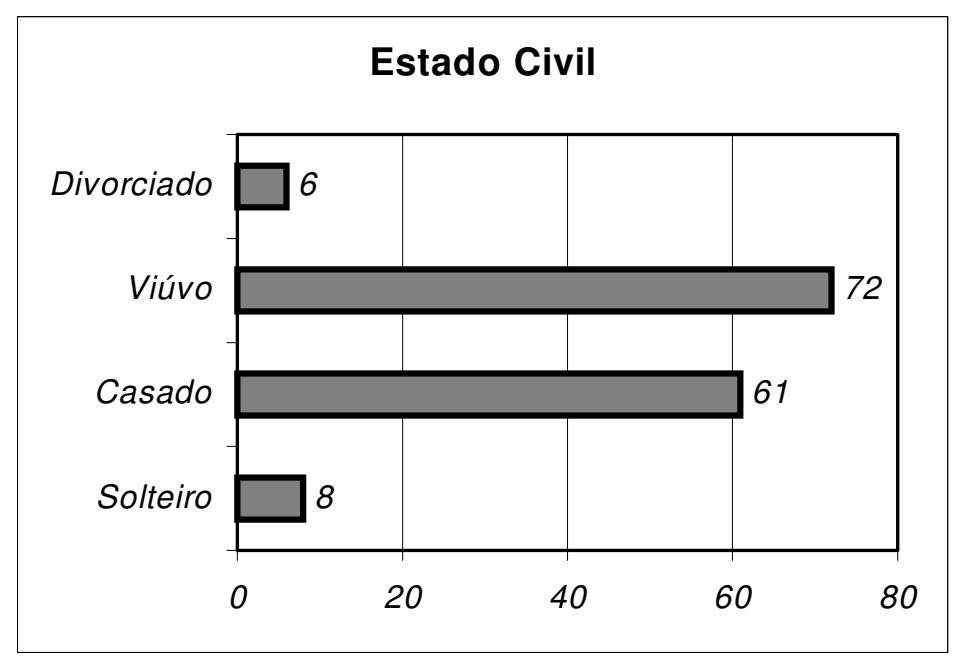

GRÁFICO 4: Estado civil da amostra ( $\mathrm{N}=147)$

Fonte: Pesquisa de Campo

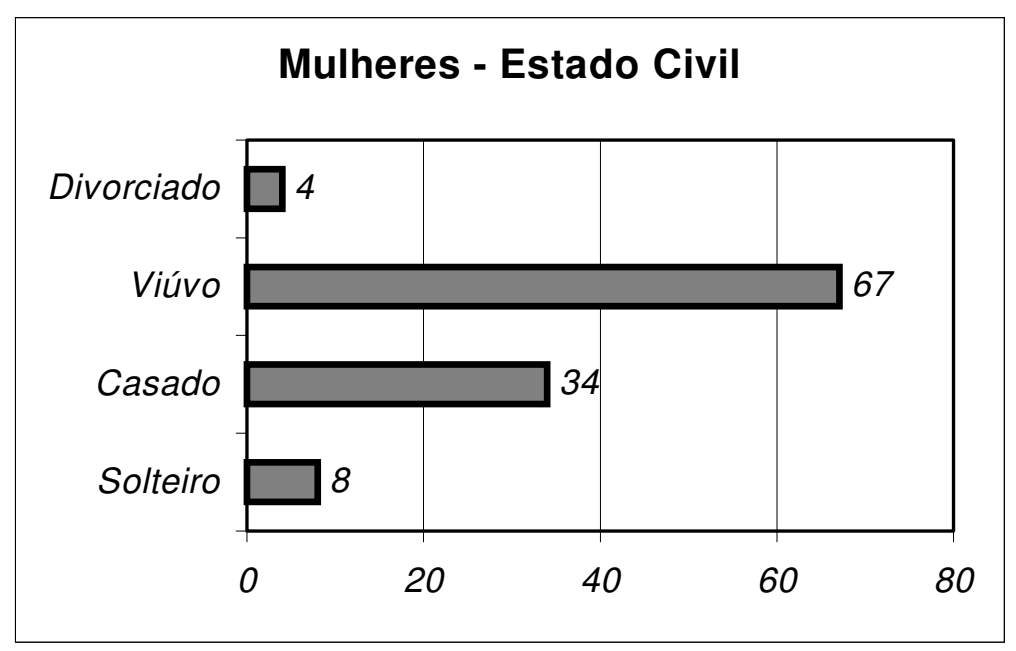

GRÁFICO 5: Estado civil das mulheres ( $\mathrm{N}=113)$

Fonte: Pesquisa de Campo

Quanto ao estado civil, encontramos que $49 \%$ dos idosos são viúvos e $41 \%$ são casados (Gráfico 4). Já falando-se especificamente das mulheres, a porcentagem de viúvas aumenta para $59 \%$ e a de casadas, cai para $30 \%$ (Gráfico 5). 
Segundo Camarano et al. (1999), a predominância da população feminina entre os idosos é comprovada internacionalmente, tendo elas uma tendência maior a viverem sozinhas. Um dos fatores apontados para este fenômeno é o fato de que o recasamento é maior entre os homens, que normalmente casam-se com mulheres mais jovens.

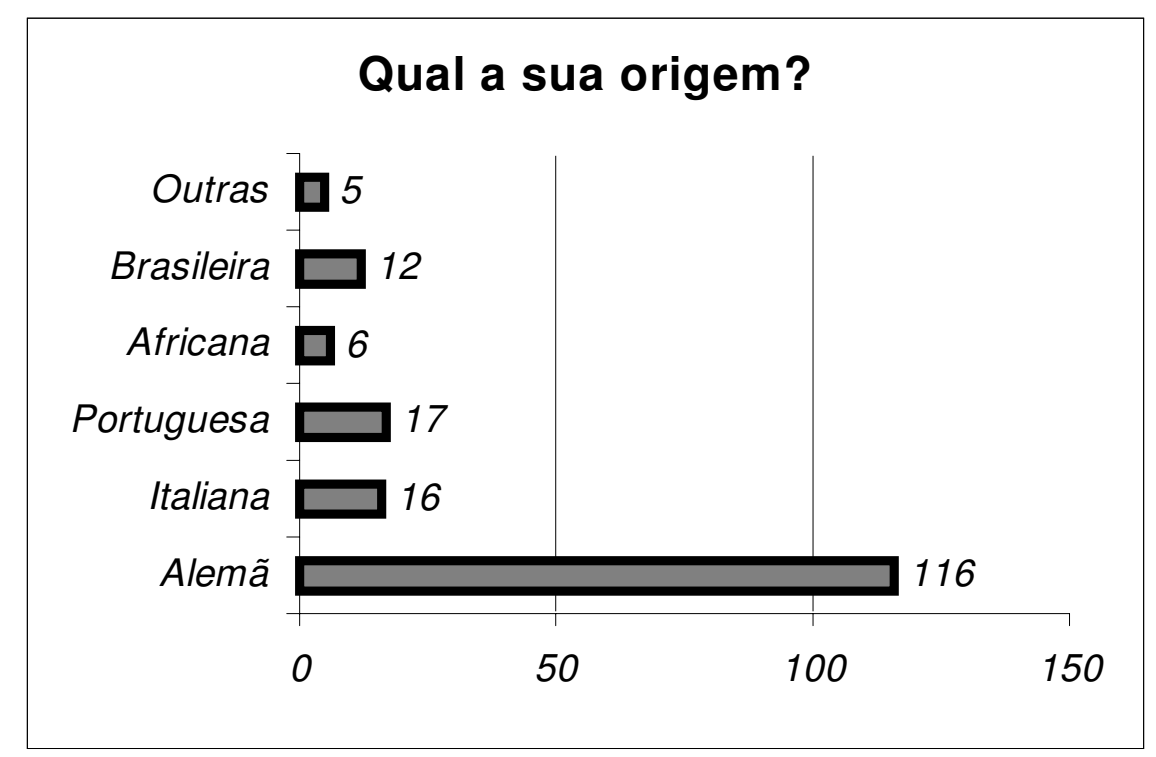

GRÁFICO 6: Origem dos idosos entrevistados

Fonte: Pesquisa de campo

Nota: Esta questão era de múltipla escolha

Em relação a origem, observando-se o Gráfico 6, verifica-se que 67\% dos idosos consideram-se de origem alemã, $10 \%$ portuguesa, $9 \%$ italiana, $7 \%$ brasileira, $3 \%$ africana e $3 \%$ de outras origens. Cabe ressaltar que algumas pessoas relataram possuir mais de uma origem. Verifica-se, assim, que o idoso de Santa Cruz do Sul, na sua grande maioria, é de origem alemã, e que talvez tenha migrado da zona rural para a urbana. Constatou-se ainda, nesta pesquisa, que $71 \%$ dos idosos sabem falar outro idioma, sendo que, destes, $86 \%$ falam o alemão. Quanto ao tempo que moram em Santa Cruz do Sul, $24 \%$ dos idosos sempre moraram no município, $33 \%$ moram no intervalo de trinta e um a cinqüenta anos, $20 \%$ moram a mais de cinqüenta anos, $10 \%$ moram entre vinte e um e trinta anos, $9 \%$ entre onze e vinte anos, $2 \%$ entre cinco e dez anos e apenas $2 \%$ moram a menos de cinco anos. 


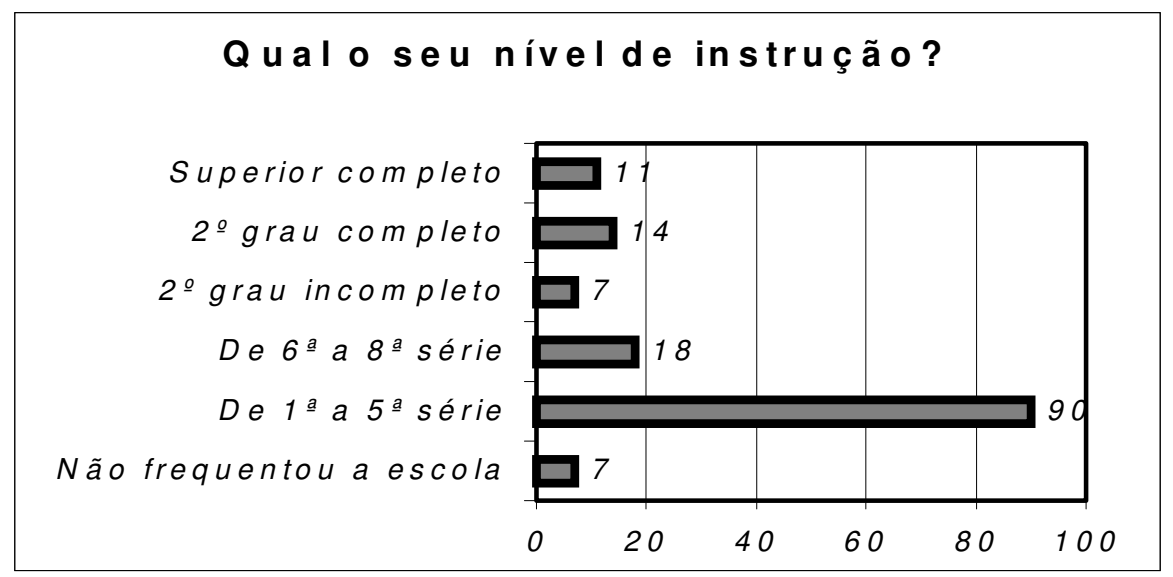

GRÁFICO 7: Nível de instrução (N=147)

Fonte: Pesquisa de Campo

Segundo o grau de instrução, $61 \%$ estudaram no intervalo de $1^{\mathrm{a}}$ a $5^{\mathrm{a}}$ série (designado pelos idosos como "primário"), $12 \%$ de $6^{\mathrm{a}}$ a $8^{\mathrm{a}}$ série, $10 \%$ possuem $2^{\circ}$ grau completo, $7 \%$ ensino superior completo, $5 \% 2^{\circ}$ grau incompleto e $5 \%$ não freqüentaram a escola (Gráfico 7). A realidade deste estudo é privilegiada em relação aos dados nacionais, onde encontrou-se uma proporção de $41 \%$ de mulheres e 37\% de homens analfabetos em 1996, nesta faixa etária (MADEIRA, 1998, apud CAMARANO). ${ }^{3}$

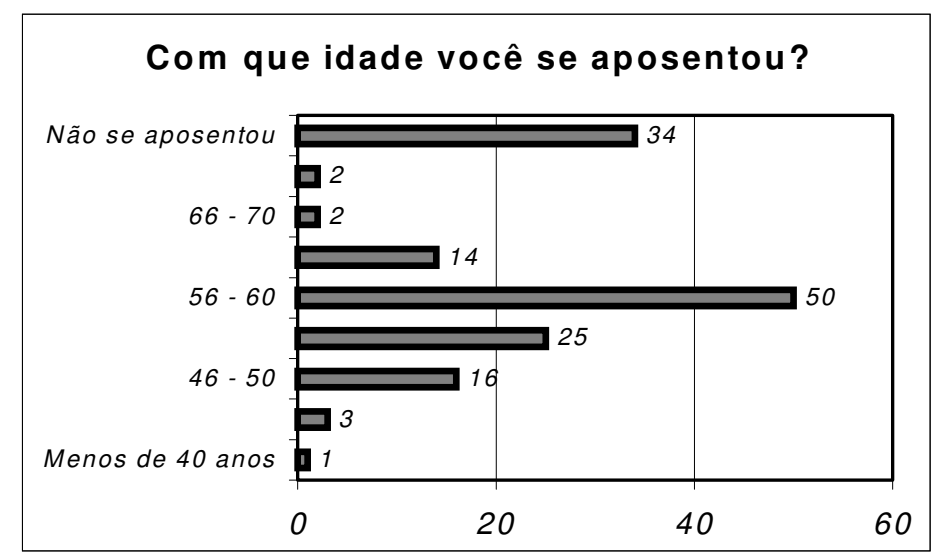

GRÁFICO 8: Idade da aposentadoria $(\mathrm{N}=147)$

Fonte: Pesquisa de Campo

${ }^{3}$ MADEIRA, F. R. Recado dos Jovens: mais qualificação. Jovens Acontecendo na Trilha das Políticas Públicas. Brasília, CNPD, 1998, p. 462. Apud CAMARANO et al., 1999. P. 43. 
Em relação a situação econômica, quanto à atividade profissional que exerceu por mais tempo, dentre as mulheres, $26 \%$ responderam serem donas de casa, $13 \%$ agricultoras, $10 \%$ safristas e $10 \%$ trabalharam no comércio. Já entre os homens, $15 \%$ identificam-se como profissionais autônomos, $15 \%$ como comerciantes, $13 \%$ como funcionários públicos, $10 \%$ eram industriários e $10 \%$ agricultores. Em relação à idade da aposentadoria (Gráfico 8), 34\% da amostra aposentou-se no intervalo entre 56 e 60 anos, $23 \%$ não aposentou-se, $17 \%$ aposentou-se entre 51 e 55 anos, $11 \%$ entre 46 e 50 anos e $10 \%$ entre 61 e 65 anos. Quanto à participação na renda familiar, $34 \%$ são aposentados e se mantêm sozinhos; $27 \%$ são aposentados e recebem ajuda de outros para suprir seus gastos; $22 \%$ não trabalham, nem são aposentados e recebem ajuda de outros ou pensão; $16 \%$ são aposentados e responsáveis pelo sustento de outros; e 1\% trabalham e são aposentados. Observa-se que apenas $10 \%$ aposentaram-se ao entrar na terceira idade, sendo que a maioria (61\%), aposentou-se antes, o que é característico do sistema previdenciário brasileiro.

Witczak (2001) nos diz que os velhos, no momento da aposentadoria formal, identificam-se como trabalhadores que foram e com todas significações decorrentes dessa identificação, reafirmando-se nos rótulos de trabalhadores aposentados. Para o autor, eles encontram no passado a significação para suas vidas presentes: "Nesta tentativa, resta-lhes o tempo da memória, rico em significantes para o presente." (p. 115).

Segundo dados de pesquisa, em 1998 os idosos eram responsáveis por uma contribuição importante na renda das suas famílias e seu rendimento era responsável por quase $53 \%$ da renda das famílias que tinham idosos. As mulheres contribuíam menos, mas mesmo assim, contribuíam com aproximadamente $44 \%$ da renda familiar (CAMARANO, 2001). 


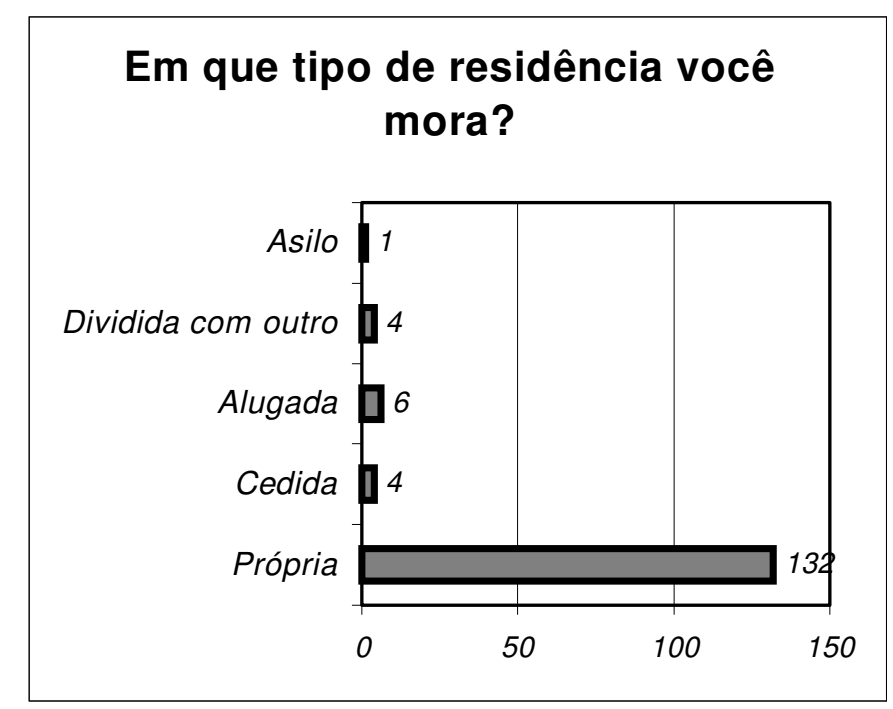

GRÁFICO 9: Tipos de residência $(n=147)$

Fonte: Pesquisa de Campo

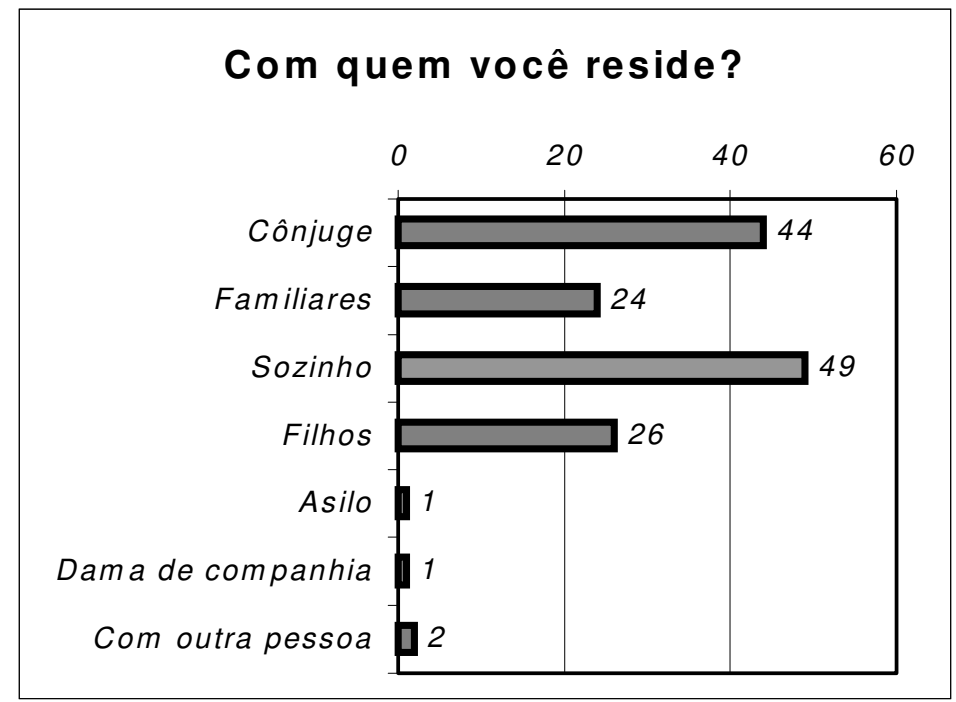

GRÁFICO 10: Com quem residem os idosos ( $\mathrm{N}=147)$

Fonte: Pesquisa de Campo

Em relação à residência, 90\% possuem residência própria, $4 \%$ alugada, $3 \%$ cedida, $3 \%$ dividida com outro e $1 \%$ mora em asilo. Quanto à questão "Com quem você reside?", $33 \%$ dos idosos moram sozinhos, $30 \%$ com o 
cônjuge, $18 \%$ com os filhos e $16 \%$ com familiares. Sabe-se que no Brasil existem 1,6 milhão de idosos vivendo sozinhos, e destes apenas 33\% são homens. O mesmo ocorre com os idosos desta pesquisa, como já ficou evidenciado ao vermos o estado civil (Gráfico 4 e 5).

O fato da grande maioria dos idosos possuírem casa própria talvez seja conseqüência de a terem adquirido enquanto faziam parte da população economicamente ativa (PEA), quando havia incentivo do sistema habitacional. Barros, Mendonça e Santos (1999) salientam que há uma tendência ao aumento da renda domiciliar através do apoio material dado pelo idoso aos demais membros de sua família. Isso se deve, em grande parte, pelo fato de os idosos se encontrarem em melhores condições materiais de vida. Uma evidência disso é dada pela proporção dos chefes que moravam em casa própria. A proporção de chefes homens que moravam em casa própria, em 1997, cresce com a idade até 75 anos e, entre as chefes mulheres, até os 65 anos.

Com relação as atividades que os idosos realizam no seu dia-a-dia, o questionário pedia para que eles escolhessem três atividades que mais gostavam de fazer, e encontramos que: $13 \%$ preferem participar dos grupos, $10 \%$ gostam de ler, $9 \%$ de olhar TV, $8 \%$ de conversar com amigos, $8 \%$ escolheram as atividades religiosas, $7 \%$ dançar, $7 \%$ jogar e $7 \%$ gostam de passear.

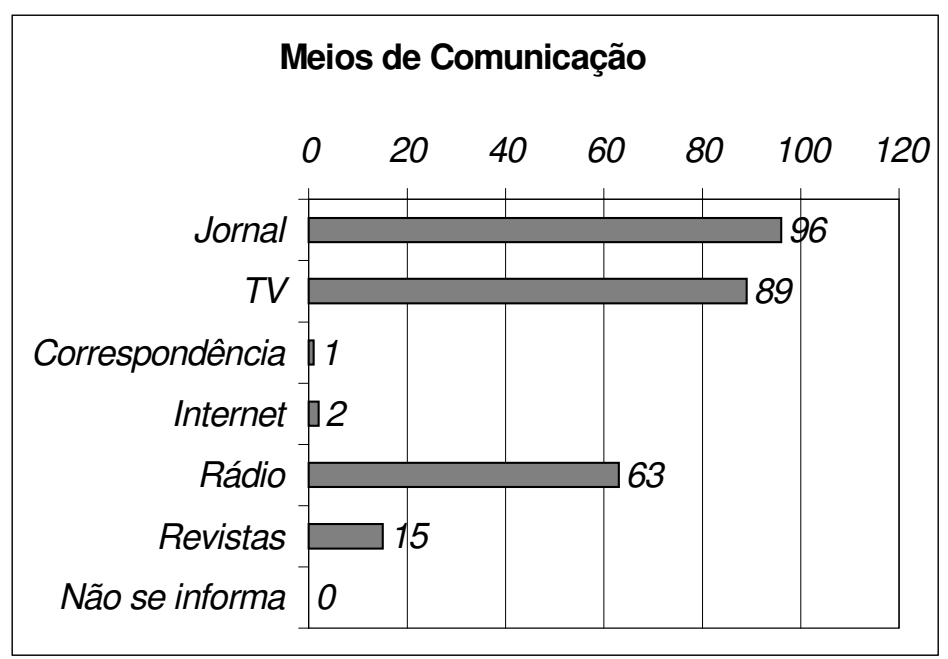

GRÁFICO 11: Meios de comunicação utilizados pelos idosos

Fonte: Pesquisa de Campo

Nota: Esta questão era de múltipla escolha. 
Quanto aos meios de comunicação utilizados para manterem-se informados, $36 \%$ preferem o jornal, $33 \%$ a TV, e $24 \%$ o rádio. É importante notar que nenhum idoso respondeu que não se informa (Gráfico 11).

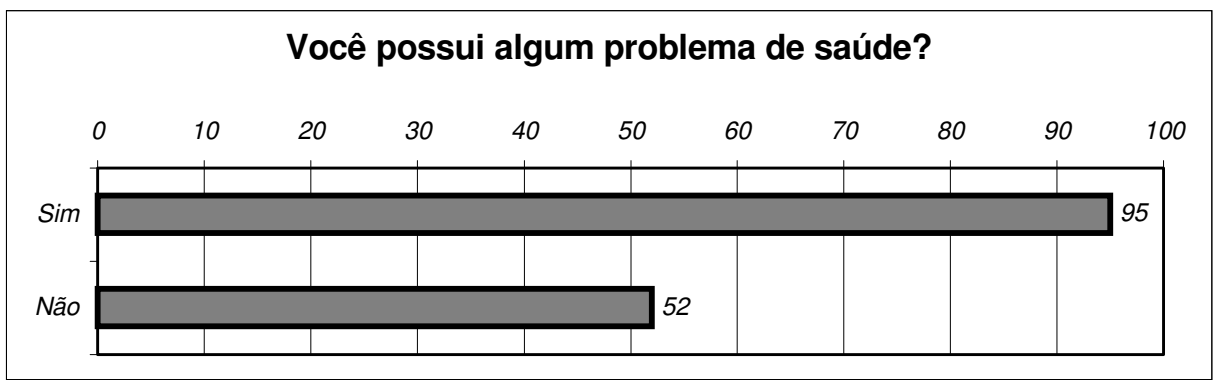

GRÁFICO 12: Problemas de saúde (N=147)

Fonte: Pesquisa de Campo

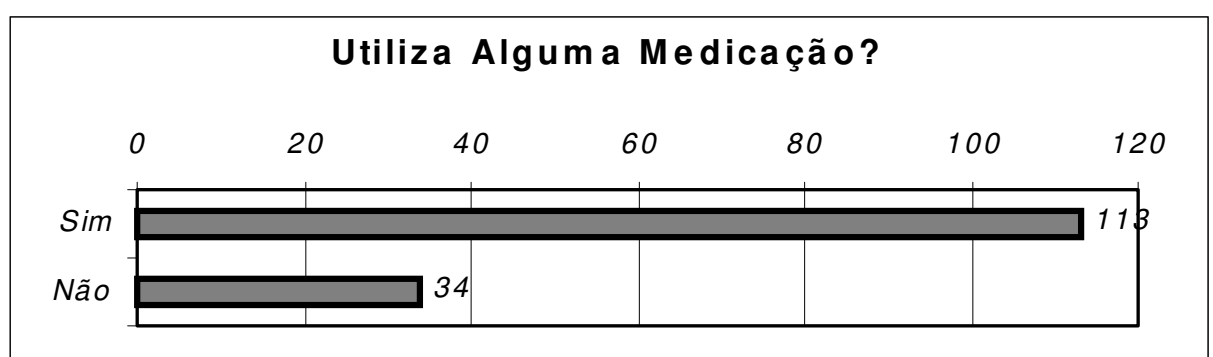

GRÁFICO 13: Medicação (N=147)

Fonte: Pesquisa de Campo

Em relação ao aspecto saúde, $77 \%$ dos idosos dizem fazer uso de algum medicamento, porém apenas $65 \%$ da amostra considera que possui algum problema de saúde, como pode ser observado no Gráfico 12 e Gráfico 13. Cockerham, Sharpe Wilcox ${ }^{4}$, citados por Medeiros, referem que a percepção do estado de saúde varia não só com os traços de personalidade, como também com a idade. Falam que as ligações afetivas dos familiares, da comunidade e de quem assiste aos idosos são suportes fundamentais para a sensação subjetiva de bem-estar e saúde dos mais velhos.

O envelhecimento populacional no Brasil é um fato recente, dado às descobertas e novas tecnologias, principalmente na área da saúde. É um

${ }^{4}$ COCKERMAN, W. C.; SHARP, K.; WILCOX, J. A. Aging an Peceived Health Status. Journal of Gerontology, Washington, n. 38, p. 349-355, 1983. Apud MEDEIROS, 1994. P. 11. 
novo fenômeno que está ocorrendo, e os grupos sociais devem ajustar-se a esta nova ordem, onde os mais velhos estão vivos, com perspectivas de longos anos. Contudo, pouco lhes é oferecido, pois a sociedade não estava acostumada com estes novos sócios, que forçam mudanças nas relações humanas de toda a ordem (afetiva, econômica, na saúde, no lazer).

\section{Considerações Finais}

Faz-se necessário, então, criar um novo vocábulo para designar mais respeitosamente a representação dos jovens aposentados - surge assim a terceira idade. Sinônimo de envelhecimento ativo e independente, a terceira idade converte-se em uma nova etapa da vida, em que a ociosidade simboliza a prática de novas atividades sob o signo do dinamismo (PEIXOTO, 2000). E é importante ressaltar que todos os sujeitos desta pesquisa se utilizam de meios de comunicação para manterem-se informados e, entre as atividades que os mesmos fazem no seu dia-a-dia, percebe-se o interesse pela vida (ler, olhar TV, passear, dançar, jogar, conviver, etc.). Parece, então, que a tendência a rotular o idoso como dependente também tem seus dias contados. As pesquisas realizadas junto ao Instituto de Pesquisa Econômica Aplicada (IPEA) vêm mostrando que é crescente o número de idosos chefes de família, e que estes é quem têm mantido, através de seus rendimentos (aposentadoria e pensões), a família fora dos índices mais baixos de pobreza (CAMARANO, 1999, 2001). Em nossa pesquisa encontramos 50\% dos idosos em condição de auto-sustento ou até responsável pelo sustento da família e $90 \%$ dos idosos morando em residência própria. Precisamos, então, modificar nossas representações em relação à velhice e passar a conviver com esses novos atores em todos os ambientes, passando para uma relação de troca e não mais de benevolência.

Além disto, o estudo nos mostra diferenças no modo como homens e mulheres estão enfrentando a velhice, o que aparece já na percentagem de idosas que freqüentam grupos de convivência para terceira idade (77\%), e que pode representar uma apropriação do espaço público após a entrada nesta nova etapa do desenvolvimento, ou mesmo após a viuvez, já que 59\% das idosas encontram-se nessa situação. 
Pensar a velhice como uma experiência homogênea é considerar os problemas enfrentados pelos idosos como semelhantes, minimizando as diferenças de gênero. Isso ocorre porque a sociedade moderna não previu um papel específico ou uma atividade para os velhos, abandonando-os a uma existência sem significado. Ou, legando-lhes a transmissão da memória coletiva, como marca do próprio envelhecer.

Para priorizar a qualidade de vida dessa população crescente, observa-se a importância de serem realizadas pesquisas nesta área para dar suporte às políticas públicas, a fim de serem atendidas as reais necessidades dos idosos.

\title{
SOCIAL REPRESENTATIONSOF OLD-AGEDPEOPLEWHO PARTICIPE OFTHIRDAGEGROUPSINSANTA CRUZDOSUL CITY
}

\begin{abstract}
This research intented to verify if the old-aged people of Santa Cruz do $\mathrm{Sul} / \mathrm{RS}$, who frequent some familiarity group is also changing the way of representing the oldness and which are the culture e region influences in this section. We intend to verify by a mixed questionary (with opened and closed questions) applyed to $10 \%$ of the old-aged people that frequent the familiarity groups in this municipality, who the old aged people of Santa Cruz do Sul are, that frequent the groups, in which condictions they live and how they occupy the free time. This study will be the base to understand how the social-historical factors influence the construction of old-aged people social representations. Keywords: Social Representation. Old-Aged.
\end{abstract}

\section{REFERÊNCIAS}

AREOSA, S. V. C.; OHLWEILER, Z. C. O Idoso e os Grupos de Convivência no Município de Santa Cruz do Sul: dados de pesquisa. REDES, Santa Cruz do Sul, v. 5, n. 1, p. 179-187, jan./abr. 2000.

BARROS, R. P.; MENDONÇA, R.; SANTOS, D. Incidência e Natureza da Pobreza entre Idosos no Brasil. In: CAMARANO, A. A. (Org.). Muito Além dos 60: os novos idosos brasileiros. Rio de Janeiro: IPEA, 1999. P. 221-149.

BEAUVOIR, S. A Velhice. Rio de Janeiro: Nova Fronteira, 1990. 
CAMARANO, A. A. et al. Como Vive o Idoso Brasileiro? In: CAMARANO, A. A. (Org.). Muito Além dos 60: os novos idosos brasileiros. Rio de Janeiro: IPEA, 1999. P. 19-71

CAMARANO, A. A. O Idoso Brasileiro no Mercado de Trabalho. Rio de Janeiro: IPEA, 2001.

(Org.). Muito Além dos 60: os novos idosos brasileiros. Rio de Janeiro: IPEA, 1999.

CHAIMOWICZ, F. A Saúde dos Idosos Brasileiros às Vésperas do Século XXI: problemas, projeções e alternativas. Revista de Saúde Pública, São Paulo, v. 31, n. 2, p. 184-200, abr. 1997.

DEBERT, G. G. Gênero e Envelhecimento. Estudos Feministas, Porto Alegre, v. 2, n. 3, p. 33-51, 1994.

A Reinvenção da Velhice: socialização e processos de reprivatização do envelhecimento. São Paulo: EDUSP, 1999.

GOLDFARB, D. C. Corpo, Tempo e Envelhecimento. São Paulo: Casa do Psicólogo, 1998.

GUARESCHI, P. A. Representações Sociais: avanços teóricos e epistemológicos. Temas em Psicologia da SBP, Ribeirão Preto, n. 3, p. 249256,2000 .

INSTITUTO BRASILEIRO DE GEOGRAFIA E ESTATÍSTICA. Censo Demográfico 2000: banco de dados agregados do IBGE. Disponível em: <http:/ /www.ibge.gov.br>. Acesso em: 17 nov. 2002.

MAGAlHãES, D. N. A Invenção Social da Velhice. Rio de Janeiro: Papagaio, 1989.

MEDEIROS, S. L. Saúde e Qualidade de Vida na Opinião dos Idosos. Revista Gerontologia, São Paulo, v. 2, n. 1, p. 07-12, 1994.

MINAYO, M. C. S. (Org.). Pesquisa Social: teoria, método e criatividade. Campinas: Papirus, 1987.

MOSCOVICI, S. La Psychanalyse, son image et son public. Paris: Presses Universitaires de France, 1961.

OLIVEIRA, E. A.; PASIAN, S. R.; JACQUEMIN, A. A Vivência Afetiva em Idosos. Psicologia Ciência e Profissão, Brasília, DF, v. 21, n. 1, p. 68-83, 2001. 
PEIXOTO, Clarice. Entre o Estigma e a Compaixão e os Termos Classificatórios: velho, velhote, idoso, terceira idade... In: BARROS, M. M. L. (Org.). Velhice ou Terceira Idade? Estudos antropológicos sobre identidade, memória e política. 2. ed. Rio de Janeiro: FGV, 2000. P. 69-84.

RAJCZUK, L.; CASTRO, R. C. G. Eventos Discutem Cuidados com os Idosos. Jornal da USP, São Paulo, p. 8-9, 19-25 abr. 1999.

RIO GRANDE DO SUL. Conselho Estadual do Idoso. Os Idosos do Rio Grande do Sul: estudo multidimensional de suas condições de vida: relatório de pesquisa. Porto Alegre, 1997.

SANTOS, G.; VAZ, C. Grupos da Terceira Idade, Interação e Participação Social. In: ZANELLA, A. et al. Psicologia e Práticas Sociais. Porto Alegre: ABRAPSOSUL, 1997. Seção 5, p. 355-368.

SANTOS, M. F. S.; BELO, I. Diferentes Modelos de Velhice. Revista PSICO, Porto Alegre, v. 31, n. 2, p. 31-48, jul./dez.2000.

SPINK, M. J. (Org.) Práticas Discursivas e Produção de Sentidos no Cotidiano: aproximações teóricas e metodológicas. São Paulo: Cortez, 1999.

TEIXEIRA, M. C. T. V.; SCHULZE, C. M. N.; CAMARGO, B. V. Representações Sociais Sobre a Saúde na Velhice: um diagnóstico psicossocial na rede básica de saúde. Estudos de Psicologia - Revista do Programa de PósGraduação em Psicologia da Universidade Federal do Rio Grande do Norte, Natal, n. 2, p. 351-359, jul./dez. 2002.

WITCZAK, M. V. C. Envelhecer ao Aposentar-se?: discutindo a aposentadoria masculina, o envelhecer e o subjetivar. Dissertação (Mestrado em Ciências Sociais) - Programa de Pós-graduação em Psicologia Social e Institucional, Universidade Federal do Rio Grande do Sul, Porto Alegre, 2001. 